\title{
Fotocatálise aplicada no estudo da descoloração e remoção da DQO dos percolados de aterro sanitário
}

\author{
Photocatalysis applied in the studies of decolorization and COD \\ removal of landfill leachate
}

\author{
Gisselma Batista ${ }^{1}$; Tiago Nogueira Marques Cervantes ${ }^{1}$; Gregory J. Moore ${ }^{2}$; H. de \\ Santana $^{1 *}$
}

\section{Resumo}

Neste artigo foi utilizado o processo fotocatalítico para a descoloração e remoção da DQO do chorume sobre a suspensão $\mathrm{TiO}_{2}$ em solução aquoso e irradiado com luz UV. Alguns parâmetros experimentais foram estudados para determinar a eficiência do processo. Os comportamentos da descoloração e remoção da DQO foram acompanhados por métodos espectrofotométricos e os resultados obtidos indicaram que o processo pode ser usado como um pretratamento ao processo convencional.

Palavras-chave: fotocatálise heterogênea. dióxido de titânio. Chorume. Descoloração. Remoção de DQO.

\begin{abstract}
In this paper photocatalysis processes on titanium dioxide suspension in aqueous solution illuminated with UV light are described for decolorization and Chemical Oxygen Demand (COD) removal of landfill leachate. Several operational parameters to achieve optimum efficiency are presented. The properties of the decolorization and COD removal were enhanced and studied by spectrophotometer methods. The results indicate that the process can be used as a pretreatment to the conventional processes.

Key words: Heterogeneous photocatalysis. Titanium dioxide. Leachate treatment. decolorization. COD removal.
\end{abstract}

\section{Introduction}

Population growth added to the consumption of manufactured goods in urban areas have increased the generation of solid waste that, in most of cases, are destined to landfills. In these locations, leachates are generated which have an environmental impact due to their potential for contamination. In landfills, leachate is generated by the chemical and microbial decomposition of solid waste and the passage of rainwater. When drained from the landfill, leachate resulting from combining the two sources carries dissolved and suspended materials posing a high

\footnotetext{
${ }^{1}$ Departamento de Química, Universidade Estadual de Londrina (UEL), 86057-970. Londrina - PR, Brasil

${ }^{2}$ Yardney Technical Products, Inc. East Greenwich, RI, USA.
} 
potential for contamination. The percolated liquid can reach the surface hydric collections as well as infiltrate the soil to reach groundwater, affecting their quality and therefore the ecosystem (IM et al., 2001; KJELDSEN et al., 2002).

The impact produced by leachate on the environment is directly related to its decomposition stage. Leachate generated at a new landfill, where it receives a good amount of rainwater, is characterized by an acidic $\mathrm{pH}$, high Biochemical Oxygen Demand (BOD), high value of Chemical Oxygen Demand (COD) and various potentially toxic compounds. Over the years, there has been a significant reduction in biodegradability of the waste. In this condition, the ratio of $\mathrm{BOD} / \mathrm{COD}$ results in lower values, which means less capacity for leachate retrogradations. This is explained by the fact that under these conditions, there is an accumulation of substances in the leachate that hinder biological degradation, such as fulvic and humic acids, originating from decomposition of vegetable material. These compounds also contribute significantly to the dark color of the leachate.

The method most employed in leachate treatment is a biological process; these materials have characteristics very similar to those found for domestic sewage. However, difficulty often occurs for such biological treatment of leachate. The flow and organic loading are highly variable, requiring a large area for implementation, low efficiency for stabilized or poorly biodegradable and very often the effluent does not fit in the standards established by legislation.

Generally, conventional wastewater treatment removes significant levels of $\mathrm{BOD}$ but the environmental standards for COD, $\mathrm{N}$ and color are not attained. Consequently, establishing a treatment method is very challenging due to the need of achieving a better biodegradability and possibly a complete destruction of organic pollutants contained in the leachate (BEKBOLET et al., 1996).
Since there are no economically viable processes that could allow reduction of all environmentally relevant parameters of the leachate matrix, several studies have proposed the use of an integrated process. Among them are the physicochemical process of coagulation/flocculation that, applied as a pretreatment, aims to improve the efficiency of subsequent biological treatment (SLETTEN et al., 1995; SILVA et al., 2004). Recently, an advanced oxidation process has been integrated with a conventional biological process (KOH et al., 2004; LOPEZ et al., 2004).

Aiming at developing a promising means for the treatment of leachate, this work is based on using some principles of heterogeneous catalysis to achieve an effective degradation of landfill leachate from Londrina City, Brazil.

The use of methods that lead to a higher degradation rate, producing environmentally friendly products, is a major goal of the methods referred to as "Advanced Oxidation Processes" (AOPs). These methods are based on the formation of hydroxyl radicals, which being highly reactive agents may even promote the mineralization of organic compounds (NOGUEIRA; JARDIM 1998).

Using AOPs, Cho; Hong e Hong (2002) evaluated the removal of COD samples from landfill leachate with a correlation of BOD/COD < 0.1 . For that a system containing 16 lamps of $8 \mathrm{~W}$, radiating at $254 \mathrm{~nm}, \mathrm{pH} 4.0,3 \mathrm{~g} \mathrm{~L}^{-1}$ of $\mathrm{TiO}_{2}$ and continuous bubbling of oxygen was used. After 4 and $8 \mathrm{~h}$ of irradiation, approximately $50 \%$ and $70 \%$ of COD reduction were obtained, respectively. At $\mathrm{pH} 8.6$, after $4 \mathrm{~h}$ of irradiation under the same conditions as the previous experiment, a COD reduction lower than $20 \%$ was obtained. After $8 \mathrm{~h}$ of irradiation, approximately $25 \%$ of COD reduction was obtained. Cho; Hong e Hong (2004) studied the endpoint of photocatalytic degradation for samples of leachate from Kimpo - South Korea. For their process a semi-batch system was used, with continuous bubbling of oxygen, 2 lamps 
radiating at $254 \mathrm{~nm}$, with $3 \mathrm{~g} \mathrm{~L}^{-1}$ of $\mathrm{TiO}_{2}$ and $\mathrm{pH}$ at 4.0. After 5 and $10 \mathrm{~h}$ of irradiation, $52 \%$ and $56 \%$ of COD reduction were obtained, respectively. To evaluate the efficiency of photoeletrocatalysis for a sample of leachate, Moraes e Bertazzoli (2005) used a low-pressure mercury vapor lamp with the sample immersed in a quartz flask with continuous bubbling of oxygen, at a natural $\mathrm{pH}$ of 8.0. After $60 \mathrm{~min}$ of irradiation, a COD reduction of 34 to $40 \%$ occurred, and after $90 \mathrm{~min}$ it reduced by approximately $48 \%$.

The aim of this work was to define the experimental parameters that promote the degradation of the landfill leachate from Londrina region, through the photocatalysis of $\mathrm{TiO}_{2}$ particles in suspension, thus making this process effective for decontaminating these recalcitrant systems. To understand the factors governing the leachate degradation using $\mathrm{TiO}_{2}$, a systematic study was performed on the experimental parameters affecting the decolorization and COD reduction of the local landfill compounds.

\section{Experimental}

\section{Samples}

For the experiments, the samples of leachate were collected from Londrina's landfill and then stored in the refrigerator. After filtration, the samples were diluted with ultrapure water and the $\mathrm{pH}$ was adjusted with $\mathrm{H}_{2} \mathrm{SO}_{4}$ or $\mathrm{NaOH}$ using a $\mathrm{pH}$ meter. In this work, all reagents were analytical grade and used without further purification.

\section{Irradiation Chamber}

The leachate photodegradation experiments were performed in an irradiation chamber (homemade), similar to that described in the literature (SANTANA; BONANCEA; TAKASHIMA, 2003). Aliquots of $300 \mathrm{~mL}$, containing $\mathrm{TiO}_{2}$, were placed in glass beakers of $1000 \mathrm{~mL}$ capacity under stirring and irradiated with a mercury vapor lamp of $125 \mathrm{~W}$, being at a distance of $10 \mathrm{~cm}$ above the solution.

\section{Decolorization Analysis}

To determine the percentage of decolorization of the samples, before the irradiation, they were diluted and the $\mathrm{pH}$ was adjusted with acid or base. After being filtered, their absorbances were determined. After irradiation, the samples were filtered again to eliminate the titanium dioxide, and the delta absorbances were determined.

In order to determine the spectral region of leachate maximum absorption for further decolorization measures, scans were made at wavelengths between 300 and $800 \mathrm{~nm}$ at various concentrations; however, an absorption band was not observed. Thus, it was decided to make the absorbance measurements of samples at $410 \mathrm{~nm}$ because at this wavelength the color change from brown to yellow is observed.

A calibration curve was required to verify the percentage of leachate decolorization. For this procedure, leachate samples were used in a range of concentration of 0.2 to $50 \%$. A good correlation was observed.

\section{COD Analysis}

COD measurements were performed by closed reflux colorimetric method according to Standard Methods (Method 5220 D). The digestions were performed on samples of digestive block (Hack). Borosilicate tubes were used with the dimension of $16 \times 100 \mathrm{~mm}$. The absorbance readings for the COD determination were performed in a Hach spectrophotometer.

To determine the COD by colorimetric method, solutions containing potassium dichromate (reagents digested) were used at concentrations $0.03472 \mathrm{~mol}$ $\mathrm{L}^{-1}$ or $0.00347 \mathrm{~mol} \mathrm{~L}^{-1}$. The most concentrated solution was applied to analytes with COD above $50 \mathrm{mg} \mathrm{O} \mathrm{L}^{-1}$, while the less concentrated solution 
was applied to analytes with COD between 5 and $50 \mathrm{mg} \mathrm{O}_{2} \mathrm{~L}^{-1}$.

Due to the leachate having a strong brown color, it was necessary to make dilutions of samples to achieve greater efficiency in the photocatalytic process. For degradations, dilutions were made in the ratios $1: 20,1: 10,2: 10$ and $3: 10$. The COD of sample at $1: 10$ ratio was $249.75 \mathrm{mg} \mathrm{L}^{-1}$ and could be determined by the COD curve made with the most concentrated $\mathrm{K}_{2} \mathrm{Cr}_{2} \mathrm{O}_{7}$, which was named as high range. However, after degradation of $24 \mathrm{~h}$, the COD removal was high, so its determination was made with the lower dichromate concentration, named as low range.

To more accurately determine the leachate concentration corresponding to the lowest detectable range, with respect to equipment and in relation to the linearity of the method, it was necessary to obtain a calibration curve using the low range standard. The digestion reagent used for this procedure was that containing potassium dichromate $0.0034 \mathrm{~mol}$ $\mathrm{L}^{-1}$. Dilutions of crude leachate were 1, 2, 3, 4 and $5 \%$ in ultrapure water.

\section{Results and Duscussion}

The results obtained for the decolorization and COD removal of diluted leachate samples, irradiated in solution with the presence of $\mathrm{TiO}_{2}$ particles, using different experimental parameters on the photocatalytic process, are presented below. For all decolorized samples absorbances were measured initially and following the photocatalysis. COD determinations of the samples were performed before the photocatalytic process and via the reagent of digestion for low range afterwards.

\section{Influence of time and TiO2 concentration in samples decolorization}

Table 1 lists the data relating to leachate decolorization and COD removal after the dilution 1:10. Time of irradiation and $\mathrm{TiO}_{2}$ concentration were varied but the initial $\mathrm{pH}$ of the solution was adjusted to 3.0. The reason to keep the $\mathrm{pH}$ at 3.0 for solutions, before irradiation, was under the assumption that the nature of the species in the leachate should be, in most, anionic species. At this $\mathrm{pH}$, higher absorption by $\mathrm{TiO}_{2}$ should occur because in $\mathrm{pH}$ below the point of zero charge it is expected that the surface of titanium dioxide would be positively charged, which favors the adsorption of the leachate. Despite this preliminary assessment, some exploratory experiments in basic medium were also performed, whereas the leachate could be positively charged species. Thus, the basic $\mathrm{pH}$ would have a $\mathrm{pH}$ above the point of zero charge of $\mathrm{TiO}_{2}$, favoring a negatively charged surface and the positively charged species adsorption on the particles of titanium dioxide. From this experiment, low decolorization of leachate was obtained in basic medium. Thus, work in acid medium ( $\mathrm{pH}$ 3.0) was chosen early as the standard. The results indicated that better efficiency of the leachate treatment can be explained by the adsorption of the compounds on the surface of the semiconductor, which has a direct influence on the efficiency of the photocatalytic process.

It was also verified by exploratory experiments that over 8 hours of irradiation, in any condition of $\mathrm{TiO}_{2}$ concentration, the results of the final absorbances of the samples are very close to the value of the blank, i.e., a complete decolorization of the samples occurs. Therefore, it was considered that for exposure durations above 8 hours, the concentration of $\mathrm{TiO}_{2}$ cannot be considered a significant parameter for the study of leachate samples with 1:10 dilution. 
Table 1 - Percentage of decolorization and COD removal of leachate as a function of $\mathrm{TiO}_{2}$ concentration and irradiation time in leachate samples with 1:10 dilution.

\begin{tabular}{|c|c|c|c|c|c|c|c|c|c|}
\hline $\begin{array}{l}{\left[\mathrm{TiO}_{2}\right]} \\
\left(\mathrm{g} \mathrm{L}^{-1}\right)\end{array}$ & $\begin{array}{c}\text { t } \\
\text { (h) }\end{array}$ & $\mathrm{pH}_{\mathrm{i}}$ & $\mathrm{pH}_{\mathrm{f}}$ & $\begin{array}{c}A_{i} \\
\text { (a. u.) }\end{array}$ & $\begin{array}{c}A_{f} \\
\text { (a. u.) }\end{array}$ & $\begin{array}{c}D \\
(\%)\end{array}$ & $\begin{array}{c}\mathrm{COD}_{\mathrm{i}} \\
\left(\mathrm{mgO}_{2} \mathrm{~L}^{-1}\right)\end{array}$ & $\begin{array}{c}\mathrm{COD}_{\mathrm{f}} \\
\left(\mathrm{mgO}_{2} \mathrm{~L}^{-1}\right)\end{array}$ & $\begin{array}{c}\mathrm{R}(\mathrm{COD}) \\
(\%)\end{array}$ \\
\hline 1.0 & 2 & 3.0 & 3.0 & 0.236 & 0.114 & 51.69 & 278.1 & 249.65 & 10.23 \\
\hline 1.0 & 4 & 3.0 & 3.0 & 0.236 & 0.087 & 63.13 & 278.1 & 241.86 & 13.03 \\
\hline 1.0 & 8 & 3.0 & 2.6 & 0.236 & 0.019 & 91.94 & 278.1 & 186.25 & 33.02 \\
\hline 2.0 & 2 & 3.0 & 3.1 & 0.177 & 0.039 & 77.96 & 171.87 & 117.90 & 31.40 \\
\hline 2.0 & 4 & 3.0 & 3.2 & 0.177 & 0.011 & 93.78 & 171.87 & 94.58 & 44.97 \\
\hline 2.0 & 8 & 3.0 & 3.1 & 0.356 & 0.002 & 100.00 & 249.75 & 97.25 & 61.06 \\
\hline
\end{tabular}

*Absorbance of the blank: ultrapure water $+\mathrm{TiO}_{2}$, about 0.001 a.u.; $\left[\mathrm{TiO}_{2}\right]=\mathrm{TiO}_{2}$ concentration; $\mathrm{t}=$ irradiation time; $\mathrm{pH}_{\mathrm{i}}$ and $\mathrm{pH}_{\mathrm{f}}=$ initial and final $\mathrm{pH}$, respectively; $\mathrm{A}_{\mathrm{i}}$ and $\mathrm{A}_{\mathrm{f}}=$ initial and final absorbance, respectively; $\mathrm{D}=$ Percentage of leachate decolorization; $\mathrm{COD}_{\mathrm{i}}$ and $\mathrm{COD}_{\mathrm{f}}=$ initial and final COD, respectively; $\mathrm{R}(\mathrm{COD})=$ Percentage of COD removal of leachate.

Source: author

It was observed in Table 2 that increasing decolorization was achieved by decreasing the leachate concentration.

The percentage of decolorization for the 1:10 dilution was $16.76 \%$, higher than that found for the $2: 10$ dilution and, in turn, $53.49 \%$ higher than that obtained for the $3: 10$ dilution after $4 \mathrm{~h}$ of irradiation and at pH 3.0 for all samples. For natural pH (8.4), the same tendency was observed. The 1:10 dilution showed a percentage of decolorization $14.74 \%$ higher than found for the 2:10 dilution and $36.01 \%$ higher than 3:10 dilution. Thus, it was verified that the initial leachate dilution has been a limiting factor to the decolorization efficiency. This is due to strong brownish color of the leachate, which reduces the incidence of radiation on the photocatalyst and inhibits the action of the same on the sample (BEKBOLET et al., 1996).
From the results in Table 2, it was observed that for the 1:10 dilution and $4 \mathrm{~h}$ of irradiation, the difference of COD removal was significant between conditions of the natural $\mathrm{pH}(8.4)$ and 3.0. This demonstrates the influence of $\mathrm{pH}$ on experiments, and it is considered the effect of zero charge potential of $\mathrm{TiO}_{2}$. For 2:10 and 3:10 dilutions at both $\mathrm{pH}$ values (3.0 and natural), the COD removal declines considerably due to the strong leachate coloring affecting the efficiency of the photocatalyst.

\section{Influence of $\mathrm{pH}$ on the decolorization of the samples}

In Table 3 is shown data related to decolorization and COD removal of the leachate as a function of $\mathrm{pH}$, while keeping leachate $1: 10$ dilution and $\mathrm{TiO}_{2}$ concentration of $2.0 \mathrm{~g} \mathrm{~L}^{-1}$ constant, with irradiation time of 2,4 and $8 \mathrm{~h}$. 
Table 3 - Decolorization and COD removal of leachate as a function of $\mathrm{pH}$, keeping the same leachate dilution $(1: 10), \mathrm{TiO}_{2}$ concentration $\left(2.0 \mathrm{~g} \mathrm{~L}^{-1}\right)$ in different irradiation time.

\begin{tabular}{|c|c|c|c|c|c|c|c|c|}
\hline $\begin{array}{c}\text { t } \\
\text { (h) }\end{array}$ & $\mathrm{pH}_{\mathrm{i}}$ & $\mathrm{pH}_{\mathrm{f}}$ & $\begin{array}{c}\mathbf{A}_{\mathbf{i}} \\
\text { (a. u.) }\end{array}$ & $\begin{array}{c}\mathbf{A}_{\mathbf{f}} \\
\text { (a. u.) }\end{array}$ & $\begin{array}{c}\text { D } \\
(\%)\end{array}$ & $\begin{array}{r}\mathrm{COD}_{\mathrm{i}} \\
\left(\mathrm{mgO}_{2} \mathbf{L}^{-1}\right)\end{array}$ & $\begin{array}{c}\mathrm{COD}_{\mathbf{f}} \\
\left(\mathrm{mgO}_{2} \mathbf{L}^{-1}\right)\end{array}$ & $\begin{array}{c}\mathrm{R}(\mathrm{COD}) \\
(\%)\end{array}$ \\
\hline 2 & 1.0 & 1.0 & 0.153 & 0,042 & 72.55 & 226.25 & 181.25 & 19.88 \\
\hline 4 & 1.0 & 1.0 & 0.153 & 0,033 & 78.43 & 226.25 & 181.25 & 19.88 \\
\hline 8 & 1.0 & 1.0 & 0.153 & 0,007 & 95.43 & 226.25 & 166.25 & 26.52 \\
\hline 2 & 3.0 & 3.1 & 0.177 & 0,039 & 77.96 & 171.87 & 117.9 & 31.40 \\
\hline 4 & 3.0 & 3.2 & 0.177 & 0.011 & 93.78 & 171.87 & 94.58 & 44.97 \\
\hline 8 & 3.0 & 3.1 & 0.356 & 0.002 & 100.00 & 249.75 & 97.25 & 61.06 \\
\hline 2 & 8.4 & 8.4 & 0.326 & 0.196 & 39.87 & 346.25 & 293.23 & 15.31 \\
\hline 4 & 8.4 & 8.4 & 0.326 & 0.096 & 70.55 & 171.87 & 145.25 & 15.48 \\
\hline 8 & 8.4 & 8.6 & 0.326 & 0.034 & 89.57 & 346.25 & 182.29 & 47.35 \\
\hline
\end{tabular}

*Absorbance of the blank: ultrapure water $+\mathrm{TiO} 2$, about 0.001 a.u.; $[\mathrm{TiO} 2]=\mathrm{TiO} 2$ concentration; $\mathrm{t}=$ irradiation time; $\mathrm{pHi}$ and $\mathrm{pHf}=$ initial and final $\mathrm{pH}$, respectively; Ai and $\mathrm{Af}=$ initial and final absorbance, respectively; $\mathrm{D}=$ Percentage of leachate decolorization; $\mathrm{CODi}$ and $\mathrm{CODf}=$ initial and final COD, respectively; $\mathrm{R}(\mathrm{COD})=$ Percentage of COD removal of leachate.

Source: author

It was observed in Table 2 that increasing decolorization was achieved by decreasing the leachate concentration.

The percentage of decolorization for the 1:10 dilution was $16.76 \%$, higher than that found for the 2:10 dilution and, in turn, $53.49 \%$ higher than that obtained for the $3: 10$ dilution after $4 \mathrm{~h}$ of irradiation and at $\mathrm{pH} 3.0$ for all samples. For natural $\mathrm{pH}(8.4)$, the same tendency was observed. The 1:10 dilution showed a percentage of decolorization $14.74 \%$ higher than found for the 2:10 dilution and $36.01 \%$ higher than $3: 10$ dilution. Thus, it was verified that the initial leachate dilution has been a limiting factor to the decolorization efficiency. This is due to strong brownish color of the leachate, which reduces the incidence of radiation on the photocatalyst and inhibits the action of the same on the sample (BEKBOLET et al., 1996).
From the results in Table 2, it was observed that for the 1:10 dilution and $4 \mathrm{~h}$ of irradiation, the difference of COD removal was significant between conditions of the natural $\mathrm{pH}(8.4)$ and 3.0. This demonstrates the influence of $\mathrm{pH}$ on experiments, and it is considered the effect of zero charge potential of $\mathrm{TiO}_{2}$. For 2:10 and 3:10 dilutions at both $\mathrm{pH}$ values (3.0 and natural), the COD removal declines considerably due to the strong leachate coloring affecting the efficiency of the photocatalyst.

\section{Influence of $\mathrm{pH}$ on the decolorization of the samples}

In Table 3 is shown data related to decolorization and COD removal of the leachate as a function of $\mathrm{pH}$, while keeping leachate 1:10 dilution and $\mathrm{TiO}_{2}$ concentration of $2.0 \mathrm{~g} \mathrm{~L}^{-1}$ constant, with irradiation time of 2,4 and $8 \mathrm{~h}$. 
Table 3 - Decolorization and COD removal of leachate as a function of $\mathrm{pH}$, keeping the same leachate dilution $(1: 10), \mathrm{TiO}_{2}$ concentration $\left(2.0 \mathrm{~g} \mathrm{~L}^{-1}\right)$ in different irradiation time.

\begin{tabular}{ccccccccc}
\hline $\begin{array}{c}\mathbf{t} \\
(\mathbf{h})\end{array}$ & $\mathbf{p H}_{\mathbf{i}}$ & $\mathbf{p H}_{\mathbf{f}}$ & $\begin{array}{c}\mathbf{A}_{\mathbf{i}} \\
(\mathbf{a} . \mathbf{u .})\end{array}$ & $\begin{array}{c}\mathbf{A}_{\mathbf{f}} \\
(\mathbf{a} . \mathbf{u .})\end{array}$ & $\begin{array}{c}\mathbf{D} \\
\mathbf{( \% )}\end{array}$ & $\begin{array}{c}\mathbf{C O D}_{\mathbf{i}} \\
\left(\mathbf{m g O}_{2} \mathbf{L}^{-1}\right)\end{array}$ & $\begin{array}{c}\mathbf{C O D}_{\mathbf{f}} \\
\left(\mathbf{m g O}_{2} \mathbf{L}^{-1}\right)\end{array}$ & $\begin{array}{c}\mathbf{R}(\mathbf{C O D}) \\
(\mathbf{\%})\end{array}$ \\
\hline 2 & 1.0 & 1.0 & 0.153 & 0,042 & 72.55 & 226.25 & 181.25 & 19.88 \\
4 & 1.0 & 1.0 & 0.153 & 0,033 & 78.43 & 226.25 & 181.25 & 19.88 \\
8 & 1.0 & 1.0 & 0.153 & 0,007 & 95.43 & 226.25 & 166.25 & 26.52 \\
2 & 3.0 & 3.1 & 0.177 & 0.039 & 77.96 & 171.87 & 117.9 & 31.40 \\
4 & 3.0 & 3.2 & 0.177 & 0.011 & 93.78 & 171.87 & 94.58 & 44.97 \\
8 & 3.0 & 3.1 & 0.356 & 0.002 & 100.00 & 249.75 & 97.25 & 61.06 \\
2 & 8.4 & 8.4 & 0.326 & 0.196 & 39.87 & 346.25 & 293.23 & 15.31 \\
4 & 8.4 & 8.4 & 0.326 & 0.096 & 70.55 & 171.87 & 145.25 & 15.48 \\
8 & 8.4 & 8.6 & 0.326 & 0.034 & 89.57 & 346.25 & 182.29 & 47.35 \\
\hline
\end{tabular}

*Absorbance of the blank: ultrapure water $+\mathrm{TiO} 2$, about 0.001 a.u.; $[\mathrm{TiO} 2]=\mathrm{TiO} 2$ concentration; $\mathrm{t}=$ irradiation time; $\mathrm{pHi}$ and $\mathrm{pHf}=$ initial and final $\mathrm{pH}$, respectively; $\mathrm{Ai}$ and $\mathrm{Af}=$ initial and final absorbance, respectively; $\mathrm{D}=$ Percentage of leachate decolorization; CODi and CODf = initial and final COD, respectively; R (COD) = Percentage of COD removal of leachate.

Source: author

It was observed in Table 3 that for samples irradiated at lower times than $8 \mathrm{~h}$ there is a strong influence of $\mathrm{pH}$ on decolorization of the samples. For $\mathrm{pH}$ values of 1.0 and 3.0, higher decolorizations were observed relative to the data obtained for the $\mathrm{pH}$ 8.5. For the $\mathrm{pH} 3.0$, higher decolorization was observed than at $\mathrm{pH} 1.0$ for all irradiation times studied. This fact was quite significant when compared at the time of 4 hours. At this duration it was observed that decolorization at $\mathrm{pH} 3.0$ was $15.35 \%$ higher than at $\mathrm{pH} 1.0$. At $\mathrm{pH} 1.0$, for the times of 2 and $4 \mathrm{~h}$, decolorizations of $72.55 \%$ and $78.43 \%$ were observed, respectively, which indicates that even with doubling the irradiation time, the difference of the decolorization percentage between them was only $5.88 \%$. For the $\mathrm{pH} 3.0$ at these same durations the difference was $15.82 \%$ higher, which points out that efficiency of decolorization at $\mathrm{pH} 3.0$ was higher than for $\mathrm{pH}$ 1.0.

The contribution of acidic medium towards more efficient decolorization can be better understood by considering the precipitation of humic substances in this pH. Tauchert et al. (2006) obtained 20\% of decolorization and 39\% of COD removal after precipitation of humic substances from the leachate in acid medium. Already in basic medium, the carbonate and bicarbonate ions, which are present in leachate due to its high alkalinity with respect to those ions, act as abductors of the hydroxyl radical, which may reduce the efficiency of the photocatalytic process (CHO; HONG; HONG, 2004; KURNIAWAN; LO; CHAN, 2006).

As shown in Table 3, for irradiation time of 2 $\mathrm{h}$, the decolorization at $\mathrm{pH} 3.0$ was $38.09 \%$ higher than at the natural $\mathrm{pH}$; however, for irradiation duration of $4 \mathrm{~h}$, this difference relative to natural $\mathrm{pH}$ was $23.23 \%$ and in $8 \mathrm{~h}$ of irradiation decreased to $10.43 \%$.

The results also indicate higher COD removal in acidic medium for any irradiation time. However, while at $\mathrm{pH}$ 3.0, COD removal was higher than 
natural $\mathrm{pH}$ and $\mathrm{pH} 1.0$. At the time of $4 \mathrm{~h}$, the COD removal at $\mathrm{pH} 3.0$ was $25.09 \%$ higher than at $\mathrm{pH}$ 1.0 and $29.49 \%$ higher than natural $\mathrm{pH}$. At the $8 \mathrm{~h}$ period of irradiation, the COD removal at $\mathrm{pH} 3.0$ was $34.54 \%$ higher than at $\mathrm{pH} 1.0$ and $13.71 \%$ higher than that for the natural $\mathrm{pH}$ sample.

Considering these results from the experiments of leachate decolorization, considering the difficulty of acidifying and subsequently neutralizing this effluent for disposal, it was decided to optimize the experimental parameters in natural $\mathrm{pH}$.

Influence of the nature of $U V$ radiation on the leachate decolorization

This study was conducted to determine the effect of the nature of the exciting radiation on the photocatalytic process by monitoring the decolorization and COD removal of leachate samples. To do so, the data obtained previously for the irradiation samples using the mercury vapor lamp bulb was compared with the data obtained for the samples irradiated by a mercury vapor lamp without the bulb protector.

Consideration was given to the $\mathrm{TiO}_{2}$ crystalline form anatase, which has a bandgap at $386 \mathrm{~nm}$ while the rutile crystalline form has one at 410 nm (SANTANA et al., 2007). To photo-excite a semiconductor, energy near or above the bandgap values is necessary. The mercury vapor lamp without the bulb protector has higher emission intensity between 185-400 $\mathrm{nm}$ and the one containing the bulb protector presents emission between 300-546 $\mathrm{nm}$. Thus, the emission of light more intense at the range of UV wavelength should more easily excite the anatase form than the rutile, which could have greater activity on the decolorization of the samples.

Table 4 lists the results of decolorization and COD removal of the leachate as a function of the nature of the UV radiation and exposure duration, under the conditions previously fixed at times of 2 , 4 and $8 \mathrm{~h}$ using the lamp without the bulb protector.

Table 4 - Percentage of decolorization and COD removal of leachate as a function of UV and time irradiated keeping the $\mathrm{TiO}_{2}$ concentration $\left(2.0 \mathrm{~g} \mathrm{~L}^{-1}\right)$, dilution (1:10), in natural $\mathrm{pH}$ and using a lamp without bulb.

\begin{tabular}{lcccccccc}
\hline $\begin{array}{c}\mathbf{t} \\
(\mathbf{h})\end{array}$ & $\mathbf{p H}_{\mathbf{i}}$ & $\mathbf{p H}_{\mathrm{f}}$ & $\begin{array}{c}\mathbf{A}_{\mathbf{i}} \\
(\mathbf{a} . \mathbf{u} .)\end{array}$ & $\begin{array}{c}\mathbf{A}_{\mathbf{f}} \\
(\mathbf{a} . \mathbf{u .})\end{array}$ & $\begin{array}{c}\mathbf{D} \\
(\%)\end{array}$ & $\begin{array}{c}\mathbf{C O D}_{\mathbf{i}} \\
\left(\mathbf{m g O}_{2} \mathbf{L}^{-1}\right)\end{array}$ & $\begin{array}{c}\mathbf{C O D}_{\mathrm{f}} \\
\left(\mathbf{m g O}_{2} \mathbf{L}^{-1}\right)\end{array}$ & $\begin{array}{c}\mathbf{R}(\mathbf{C O D}) \\
(\%)\end{array}$ \\
\hline 2 & 8.4 & 8.4 & 0.326 & 0.187 & 42.63 & 346.25 & 298.27 & 13.85 \\
4 & 8.4 & 8.4 & 0.326 & 0.072 & 77.91 & 346.25 & 251.25 & 27.44 \\
8 & 8.4 & 8.7 & 0.326 & 0.000 & 100.00 & 346.25 & 133.75 & 61.37 \\
\hline
\end{tabular}

\footnotetext{
*Absorbance of the blank : ultrapure water $+\mathrm{TiO} 2$, about 0.001 u.a.; $\mathrm{D}=$ fraction of dilution (leachate. : ultrapure water); $\mathrm{pHi}$ and $\mathrm{pHf}=\mathrm{pH}$ initial and final, respectively; $\mathrm{Ai}$ and $\mathrm{Af}=$ initial and final absorbance, respectively; $\mathrm{D}=$ Percentage of leachate decolorization; $\mathrm{CODi}$ and $\mathrm{CODf}=$ initial and final COD, respectively; $\mathrm{R}(\mathrm{COD})=$ Percentage of COD removal of leachate.
}

Source: author 
It was noticed that under the studied conditions, comparing the results of Table 4 and Table 3, a higher decolorization occurs when the lamp without the bulb protector is used for the irradiation, with a gain of $2.76 \%, 7.36 \%$ and $10.43 \%$ at durations of 2 , 4 and $8 \mathrm{~h}$, respectively.

With the same comparison, for times of 2 and 4 $\mathrm{h}$ of irradiation, no increase of COD removal was noticed; however, for the $8 \mathrm{~h}$ irradiation sample there is a gain of $14.02 \%$ when using the lamp without the bulb protector.

\section{Conclusions}

Comparison of decolorization and COD removal of samples under the same conditions for the photocatalytic experiments indicated that the decolorization is not a parameter that correlates directly with COD removal. For an irradiation duration of $8 \mathrm{~h}$ at natural $\mathrm{pH}$, where the decolorization was $89.57 \%$, the COD removal was only $47.35 \%$. This is due to the high organic content of these materials, demonstrating the resistance of being degraded.

With the use of the lamp without the bulb protector, it was possible to obtain higher COD removal, about $61.37 \%$. It was observed that the best results for the COD removal were comparable to those found in the literature, but COD removals in significant amounts in short periods as 60 and 90 min was not achieved.

These facts demonstrate that photocatalysis is an alternative to pretreatment, improving the decolorization and the degradation of the residual organic products present in the raw leachate for later remediation using conventional methods. This can be made possible due to the small reduction in the $\mathrm{pH}$ of the waste during the photocatalytic process; it may increase efficiency, for example of the biological treatments that provide reduction of organic loads and demonstrate removal of color, leading to an increased efficiency of the biological treatment that is susceptible to the variations of organic content and demonstrate a limited efficiency for color removal.

\section{Acknowledgements}

We would like to express our appreciation of the Spectroscopy Laboratory (SPEC) at the PROPPG/ UEL Multiuser Center. T.N.M.C aknowledges the PhD scholarship by PVE/CAPES (Project no. 124/2012).

\section{References}

BEKBOLET, M.; LINDNER, M.; WEICHGREBE, D.; BAHNEMANN, D. W. Photocatalytic detoxification with the thin-film fixed-bed reactor (TFFBR): clean-up of highly polluted landfill effluents using a novel $\mathrm{TiO}_{2}$-photocatalyst. Solar Energy, Kidlinton, v. 56, n. 5, p. 455-469, 1996.

CHO, S. P.; HONG, S. C.; HONG, S. I. Study of the end point of photocatalytic degradation of landfill leachate containing refractory matter. Chemical Engineering Journal, Lausanne, v. 98, n. 3, p. 245253, 2004.

Photocatalytic degradation of the landfill leachate containing refractory matters and nitrogen compounds. Applied Catalysis B: Environmental, Amsterdam, v. 39, n. 2, p. 125-133, 2002.

IM, J. H.; WOO, H. J.; CHOI, M. W.; HAN, K. B.; KIM, C. W. Simultaneous organic and nitrogen removal from municipal landfill leachate using an anaerobic-aerobic system. Water Research, New York, v. 35, n. 10, p. 2403-2410, 2001.

KJELDSEN, P.; BARLAZ, M. A; ROOKER, A. P.; BAUN, A.; LEDIN, A. Present and long-term composition of MSW landfill leachate: a review. Critical Reviews in Environmental Science and Technology, Boca Raton, v. 32, p. 297-336, 2002. 
KOH, I. O.; CHEN-HAMACHER, X.; HICKE, K.; THIEMANN, W. Leachate treatment by the combination of photochemical oxidation with biological process. Journal of Photochemistry and Photobiology A: Chemistry, Lausanne, v. 162, p. 261-271, 2004.

KURNIAWAN, T. A.; LO, W. H.; CHAN, G. Y. S. Radicals-catalyzed oxidation reactions for degradation of recalcitrant compounds from landfill leachate. Chemical Engineering Journal, Lausanne, v. 125, n. 1, p. 35-57, 2006.

LOPEZ, A.; PAGANO, M.; VOLPI, A.; DI PINTO, A. C. Fenton's pre-treatment of mature landfill leachate. Chemosphere, Oxford, v. 54, n. 7, p. 1005 1010, 2004.

MORAES, P. B.; BERTAZZOLI, R. Electrodegradation of landfill leachate in a flow electrochemical reactor. Chemosphere, Oxford, v. 58, p. 41-46, 2005.

NOGUEIRA, R. F.P.; JARDIM, W. F. Heterogeneous photocatalysis and its environmental applications. Química Nova, São Paulo, v. 21, n. 1, p. 69-72, 1998.

SANTANA,H.;BONANCEA,C.E.;TAKASHIMA, $K$. Photoelectrochemical degradation of atrazina on titanium dioxide: effect of different experimental parameters. Química Nova, São Paulo, v. 26, n. 6, p. 807-811, 2003.

SANTANA, H.; MACEDO, L. C.; ZAIA, D. A. M.; MOORE, G. J. Degradation of leather dye on TiO2: a study of applied experimental parameters on photoelectrocatalysis. Journal of Photochemistry and Photobiology A: Chemistry, Lausanne, v. 185, n. 1, p. 86-93, 2007. 